\title{
NAVEGAR EM ONDAS FASCISTAS NÃO É PRECISO!
}

\author{
Navigating waves of fascism is not necessary!
}

\author{
Marco Antônio Margarido COSTA \\ Universidade Federal de Campina Grande \\ marcoantoniomcosta@gmail.com \\ https://orcid.org/0000-0002-5282-2618
}

O documentário \#AnneFrank: vidas paralelas $^{1}$ rememora eventos registrados no famoso diário da adolescente judia morta pelo nazismo na Segunda Guerra Mundial (1939-1945). Filmes e documentários sobre esse período são inúmeros e, quando se supõe que as possibilidades foram todas esgotadas, há sempre uma recente produção ganhando notoriedade, como é o caso do mencionado documentário. Embora os horrores do nazismo tenham sido expostos e explorados na literatura e no cinema com abundância, é sempre necessário (re)visitá-los na tentativa de não corrermos o risco de que descalabros similares voltem a acontecer.

Em meio a momentos da breve vida de Anne Frank, o documentário traz depoimentos impactantes de sobreviventes e de vários estudiosos e historiadores, dentre os quais, destaco o do diretor da Fundação Anne Frank, Ronald Leopold. Para ele, manter totalmente vazio o local que serviu de esconderijo para a jovem judia é necessário para que tal espaço nos sirva como um espelho para refletir nossa imagem e nos provocar a constatação de que o horror ali vivido foi obra humana, ou seja, todo ser humano possui uma parcela de responsabilidade por cada vida brutalmente ceifada durante o holocausto.

A fala desconcertante do diretor incomoda não apenas pelo modo como nos posiciona diante das atrocidades cometidas contra milhões de judeus durante a Segunda Guerra Mundial, mas também pela forma como nos convoca a ter uma reação e a jamais permitir que os valores preconizados pelo nazismo possam ganhar proporções incontroláveis novamente na sociedade. Esse sinal de alerta me remete à autocrítica igualmente provocante de Pêcheux ([1975] 1997), ao romper com seus escritos iniciais,

\footnotetext{
${ }^{1}$ \#AnneFrank: vidas paralelas. Direção: Sabina Fedeli e Anna Migotto. Produção: 3D Produzioni. Itália, 2019 (94 min). Netflix. Web. Acesso em: 5 jul. 2020.
} 
em seu clássico estudo sobre semântica e discurso:

[...] não se deixa jamais um erro dormir impunemente em paz, pois esse será um meio seguro para que ele perdure; é preciso discernir o que falha não por pretender com isso se amparar definitivamente no verdadeiro (!), mas para tentar avançar tanto quanto se possa em direção à justiça. (PÊCHEUX, 1997, p. 299, grifos meus).

Acolhendo a ponderação do diretor da Fundação Anne Frank e também com base nesse fragmento da autocrítica pecheutiana, neste texto, pretendo refletir sobre essa responsabilização pelo "erro" ("falha") cometido, como também sobre uma possível condição para "tentar avançar tanto quanto se possa em direção à justiça", que se traduz aqui em uma tentativa de se evitar que seguidores e apoiadores de visões e atitudes autoritárias nazifascistas "durma[m] impunemente em paz".

Inicialmente, caberia questionar em que medida falhamos como seres humanos frente ao extermínio dos judeus e por que essa mesma falha ainda se insinua e nos ameaça nos dias atuais. Esse questionamento me remete novamente ao cinema para resgatar o filme $A$ onda (Die Welle $)^{2}$, no qual, frente à certeza de um grupo de alunos(as) acerca da impossibilidade de que um novo governo ditatorial pudesse surgir na Alemanha, o professor realiza uma experiência com o objetivo de demonstrar a facilidade da manipulação das massas.

Ambos, o documentário e o filme, abordam algo muito caro para os estudos discursivos, qual seja a noção de memória discursiva. Devolvendo a palavra a Pêcheux:

[...] a memória discursiva seria aquilo que, face a um texto que surge como acontecimento a ler, vem restabelecer os "implícitos" (quer dizer, mais tecnicamente, os pré-construídos, elementos citados e relatados, discursos-transversos, etc.) de que sua leitura necessita: a condição do legível em relação ao próprio legível. (PÊCHEUX, 1999, p. 52).

\footnotetext{
${ }^{2}$ A onda. Direção: Dennis Gansel. Constantin Film Distribution GmbH. Alemanha, 2008 (107 min). Esse filme foi baseado no livro homônimo de Todd Strasser, publicado em 1981, o qual aborda um movimento conhecido como A terceira onda. Trata-se de um experimento realizado em 1967, nos Estados Unidos, com alunos(as) do ensino médio de uma escola californiana, em que o professor de História, a fim de problematizar a alegação da falta de conhecimento por parte da sociedade alemã em relação ao extermínio dos judeus, determina que uma série de padrões e comportamentos sejam rigidamente seguidos, na tentativa de se extinguir a democracia.
} 
Para os propósitos deste texto, não abordarei o funcionamento de cada um dos "implícitos" listados, mas me concentrarei mais particularmente sobre o regime da repetibilidade ${ }^{3}$ e, por consequência, do efeito de esquecimento, presentes nesses implícitos e que tornam uma determinada materialidade ("texto que surge") possível de ser lida a partir de alguns sentidos já produzidos. Nas duas materialidades textuais legíveis (documentário e filme), encontramos estímulos que ativam uma memória discursiva e previnem, portanto, o esquecimento, uma vez que ocorrem simultaneamente. No caso da fala do diretor da Fundação Anne Frank, manter o esconderijo vazio foi uma maneira de se preservar a história ali vivida - e que descortina todo o horror do holocausto - sempre ativa e latejante. Na película alemã, o experimento realizado pelo professor também funciona como um mecanismo para se resgatar e trazer à superfície um sentido já produzido (condição do legível) que, embora aparentemente esquecido, manifesta-se com roupagem contemporânea ("novas" ressignificações). Em outras palavras, os sentidos produzidos e possíveis de serem lidos sobre o vazio do esconderijo, assim como sobre a experiência de reconstituição de um regime ditatorial, evidenciam-se em função da repetição de discursos manifestados por meio de enunciados, pensamentos, atitudes, comandos, etc. Com efeito, sobre essa questão, é exemplar a obra de Klemperer (2009), cuja tese é a de que o nazismo na Alemanha se consolidou quando dominou a linguagem, "por meio de palavras, expressões e frases impostas pela repetição, milhares de vezes, e aceitas inconsciente e mecanicamente" (p. 55).

É sabido que a literatura e o cinema nos colocam constantemente em contato com um imaginário (conjunto de discursos possíveis) sobre questões e realidades variadas como os regimes antidemocráticos, por exemplo - com os quais os sujeitos estabelecem vínculos de naturezas diversas em função dos diferentes contextos e modos, por meio dos quais foram interpelados por tais discursos. Poderíamos continuar listando vários outros trabalhos em que foram retratadas histórias violentas envolvendo, por exemplo, o desaparecimento e a tortura de presos políticos perseguidos pela ditadura militar no Brasil e em grande parte da América Latina, na África, etc., mas é praticamente impossível tratar de tais questões em poucas páginas. O que me interessa aqui é tentar refletir sobre o fato

\footnotetext{
${ }^{3}$ No sentido proposto por Indursky (2011), ao tratar de diversos funcionamentos discursivos por meio dos quais a memória se manifesta no discurso. Para a autora, "não dá para interpretar uma atualidade sem mobilizar a memória” (p. 86).
} 
de que todas as histórias e sofrimentos de vítimas de regimes nazifascistas estampadas permanentemente na nossa história, na mídia, no cinema, na literatura, etc., não foram/são suficientes para impedir o ressurgimento de qualquer forma de regime político ditatorial na sociedade. Concebe-se assim que a repetibilidade como mecanismo de prevenção pode "falhar" e adquirir ressignificações perigosas. Nesse caso, a hipótese que me orienta é a de que há um fascínio deliberado pela violência, pela injustiça e pela desumanidade que tais regimes representam.

Se essa hipótese estiver correta, cabe questionar em que medida se pode pensar em responsabilização, por não se ter evitado que pensamentos e atitudes antidemocráticas voltassem a se manifestar de forma tão escancarada no Brasil, após a última eleição presidencial de 2018, quando um candidato, apesar de todas as demonstrações antidemocráticas alinhadas com a ditadura militar - que nos envergonha pela truculência e violência praticadas - foi alçado ao cargo de chefe do Executivo nacional. O que faz com que as histórias de violência e horror vividas pelo povo brasileiro nos duros anos da ditadura militar, e apreciadas por esse representante, não tenham se prestado a conter a onda de apoiadores que se alastrou como uma epidemia pelo país? Estariam todos esses apoiadores imbuídos de um desejo de viver novamente o que pensadores, educadores, acadêmicos, historiadores, cidadãos honestos, íntegros e compromissados com o Brasil vêm tentando combater desde que a ditadura militar se encerrou no país?

$\mathrm{Na}$ tentativa de buscar compreender um pouco essa onda que assolou o país, cujas peculiaridades nocivas denotam características fascistas, recorro ao estudo filosófico de Stanley ([1969] 2018, p. 6) sobre o fascismo, termo por ele utilizado para designar "qualquer tipo de ultranacionalismo (étnico, religioso, cultural), no qual a nação é representada na figura de um líder autoritário que fala em seu nome”. Conforme o autor, a política fascista inclui muitas estratégias diferentes, entre as quais saliento: o passado mítico e o anti-intelectualismo. ${ }^{4}$ Creio ser viável encontrar situações geradas e ações empreendidas pelo principal mandatário do país que são representativas de cada uma das estratégias citadas. Contudo, exemplifico apenas duas, iniciando pela estratégia do passado mítico. Para tanto, tomo como epítome dessa estratégia a menção elogiosa proferida publicamente pelo então deputado federal, agora presidente, a um coronel

\footnotetext{
${ }^{4}$ As demais estratégias são: a propaganda, a irrealidade, a hierarquia, a vitimização, a lei e a ordem, a ansiedade sexual, apelos à noção de pátria e a desarticulação da união e do bem-estar público.
} 
reconhecidamente torturador vinculado à ditadura militar no Brasil. ${ }^{5} \mathrm{~A}$ onda nostálgica patológica acomete (ou desperta?) também uma famosa atriz brasileira nomeada (já substituída) para exercer o cargo de Secretária Especial da Cultura que, em entrevista a uma emissora de TV, entoa um trecho de uma canção marcadamente atrelada à ditadura militar no Brasil, finalizando com o seguinte questionamento ao entrevistador: "Não era bom quando a gente cantava isso?". 6

Uma segunda estratégia bastante ilustrativa diz respeito ao anti-intelectualismo, manifestado pelo presidente, por exemplo, ao tentar banir Paulo Freire, eminente pensador e educador brasileiro mundialmente reconhecido pelas suas reflexões e contribuições para a educação. No mesmo campo educacional, é ilustrativa também a nomeação de um Ministro de Estado da Educação declaradamente preconceituoso, truculento e medíocre em suas posições e manifestações públicas, nas quais depreciava universidades e professores. ${ }^{7}$

Esses breves recortes de demonstrações das estratégias do funcionamento do fascismo evidenciam o desejo deliberado de uma (re)atualização, ou uma condição para tornar legível um período nefasto de nossa história brasileira. Como discernir o que falhou, no sentido pecheutiano de autocrítica? Tendo a considerar que a falha não diz respeito ao "inocente" esquecimento dos apoiadores do presidente em relação a um passado que, embora trágico, tentam mitificar, tampouco diz respeito à pouca visibilidade das cicatrizes deixadas pela ditadura no Brasil. A interpretação de que grande parte dos votos foi em protesto contra o partido que governou o país por mais de 13 anos, antes de 2018, também não parece ser suficiente. Tais interpretações não satisfazem, uma vez que nossa memória discursiva, que é de ordem ideológica (cf. INDURSKY, 2011), não encontra um registro de sentido já produzido que torne legível a eleição do presidente em questão. Evidencia-se assim uma "falha" anterior, qual seja a nossa incapacidade de acolher nossas próprias diferenças e contradições como condição legível de nossa própria subjetividade. Cala em mim a suspeita de que essa necessária re(atualização) e o

\footnotetext{
${ }^{5}$ Trata-se da menção ao coronel Carlos Alberto Brilhante Ustra proferida por Jair Messias Bolsonaro durante sessão da Câmara dos Deputados realizada em 17 de abril de 2016, na qual ocorreu a votação para a instauração do processo de impeachment contra a presidente Dilma Rousseff.

${ }^{6}$ Estou me referindo a Regina Duarte, cuja nomeação para o mencionado cargo ocorreu em 3 de março de 2020.

${ }^{7}$ Refiro-me a Abraham Weintraub, nomeado em 8 de abril de 2019, que permaneceu no cargo por 14 meses.
} 
acolhimento dessas diferenças e contradições interiores possam nos ajudar a compreender que o legível evidenciado pela rede de sentidos associada ao presidente esteve sempre presente, nós apenas desacreditamos a sua efetiva "(re)inserção" na história política brasileira, assim como os(as) alunos(as) da experiência realizada no filme $A$ onda.

Diante de um processo de desmoronamento social orquestrado pelo atual governo federal, suspeito que desponta (ou ratifica) um aprendizado possível: a compreensão de que o regime da repetibilidade permite que um sentido seja retomado, mas esse mesmo sentido pode (e deve, muitas vezes) ser desregularizado e transformado em outro (como no caso do "esconderijo" de Anne Frank). Ou seja, ainda é factível intervir nos sentidos retomados no contexto político aqui tratado, agregando formulações de resistência (produção de contradiscursos) que contribuam para a (re)construção de uma memória social que efetivamente previna erros, como foi a escolha do atual ocupante da presidência da república do Brasil.

\section{REFERÊNCIAS}

INDURSKY, F. A memória na cena do discurso. In: INDURSKY, F.; MITTMANN, S.; FERREIRA, M. C. L. (Orgs.). Memória e história na/da análise do discurso. Campinas, SP: Mercado de Letras, 2011, p. 67-89.

KLEMPERER, V. LTI: a linguagem do Terceiro Reich. Rio de Janeiro: Contraponto, 2009.

PÊCHEUX, M. Papel da memória. In: ACHARD, P. et al. (Orgs.). Papel da memória. 3. ed., Campinas, SP: Pontes Editores, 1999, p. 49-57.

PÊCHEUX, M. (1975). Semântica e discurso: uma crítica à afirmação do óbvio. 3.ed. Campinas: Ed. da UNICAMP, 1997.

STANLEY, J. (1969). Como funciona o fascismo: a política do "nós" e "eles". 1.ed. Porto Alegre, RS: L\&PM, 2018. 